\title{
The measurement of fluid pressure in rock and soil
}

\author{
I Gray Sigra Pty Ltd, Australia \\ B Neels Sigra Pty Ltd, Australia
}

\begin{abstract}
This paper reviews methods in use for measuring fluid pressure in the ground and presents some new options. It examines the traditional systems of installing piezometers in a gravel pack, current practice of grouted in transducers and, packer options, detailing their benefits and limitations extending from problems with ephemeral perched water tables to measurements in gas reservoirs. Finally, it presents two new systems for installing pressure measurement systems. The first involves cement grouting transducers in place and ensuring their connectivity to the formation by displacement of the cement around the pressure transducer tip by a fluid injection. It has been successfully used in groundwater and coal seam gas applications. The other is used to determine the fluid pressure in soils from the positive pressures to the suction range. It involves pushing multiple piezometer tips into the sidewall of the borehole and then cementing the hole. It can be combined with multiple settlement indicators within the same borehole.
\end{abstract}

\section{Introduction}

The measurement of fluid pressure in the ground has multiple purposes and involves installations in a whole range of geological environments. Despite this huge variability, the basic reasoning is to measure the pressure of a particular phase: gas, including air and steam; and liquid, which may be water or hydrocarbons.

Pressure measurement in the ground is conducted for a variety of purposes which include the assessment and monitoring of slope stability, consolidation of soft soils or reservoirs, aquifers and petroleum reservoirs. The latter may be conventional reservoirs but are increasingly becoming those that are unconventional, where the source rock is also the reservoir; these typically have very low permeability.

As with any other measuring system, we need to ask the questions:

- What are we measuring?

- How will our measurement affect the system we are trying to monitor?

\section{$2 \quad$ What are we measuring?}

The purpose of fluid pressure monitoring is to monitor the particular phase of fluid we are interested in. In civil engineering and mining situations, the fluid is typically water below the phreatic surface. Sometimes this pressure is very high, corresponding to great depth, while on other occasions it is below atmospheric pressure, corresponding to water saturated, over-consolidated clays which undergo unloading with excavation. In the case of soils in the unsaturated zone, the question arises as to what pressure is being measured: air or capillary water? Great care must be undertaken in ensuring a connection to the correct phase in these circumstances. This is generally afforded by the use of filters of the correct capillary pressure characteristics. In the latter case, the question remains, however, as to what negative pore pressure really exists in the wet capillaries.

The concept of dealing with different phases also applies to the petroleum reservoir situation where the phases being dealt with are generally gas, oil and water. There is, however, generally very little effort put into permanent pressure monitoring of reservoirs let alone the differentiation of which phase pressure is 
being measured. The reason for this is that the pressures tend to be so high that the variations caused by capillary pressure effects are generally regarded to be minor by comparison.

\section{How we affect the system we are trying to monitor}

If we drill a hole to measure fluid pressure then we alter the system by connecting various formations. We also potentially inject drilling fluid into the ground, thus changing the fluid pressure and the fluids around the hole for a period. Frequently we change the permeability immediately around the hole because we have introduced drilling fluid (including polymers) and clays from the strata being drilled, into fractures. This leads to all the well bore damage problems that are recognised in the petroleum industry.

Further changes can be induced by backfill of a borehole using bentonite/water grouts that may not be volumetrically stable with locally introduced pore pressures caused by the hydration process (Mikkelsen \& Green 2002). The use of cement grouts can further exacerbate this problem and introduce more complex issues with the creation of low perm zones around the wellbore, resulting in long pressure change response times (Neels \& Gray 2014).

It may be thought that the issues of well bore damage do not affect the measurement of pressures because pressure measurement is essentially associated with negligible flow. The real situation is that the rate of response of a pressure measuring system in the ground is dependent on the volume of fluid required to operate that system (volume per unit pressure change) and the permeability around the pressure sensing area.

\subsection{Open tube piezometers}

The reason that open tube piezometers have been used successfully for such a long period is a result of the high permeability materials they have been used to monitor and the low expectation of response rate for the device. This is largely due to the high volume per unit pressure change at which they are required to operate. The bigger the tube, the worse the situation - even more in the case of open casing.

\subsection{The behaviour of gravel packs}

Gravel or sand packs have been traditionally used around the bottom of standpipe piezometers to provide a means of connection to the ground being monitored. They are normally sealed in place by the use of bentonite plugs, or cement stabilised bentonite grout. For both single and multiple transducers, this can be time consuming to install. In cases where the ground surrounding the gravel pack is above the phreatic surface, it is quite possible to register apparent perched water tables during periods of rainfall. This is a result of the placement of the pressure sensing element within the gravel pack and the manner in which water passes down through the soil into and out of the gravel pack. By definition, if the pressure sensing element is in the lower portion of the gravel pack, and the ground is of uniform horizontal permeability which is greater than the uniform vertical permeability, then the base of the pack will tend to fill with water, the head of which is then measured. Experience was gained with this effect in colluvium in Hong Kong, when perched water tables were repeatedly measured during periods of heavy rain but horizontal drains installed to drain these never produced any water.

The smearing of the borehole wall in which a gravel pack is installed is also an issue as it changes the near well bore permeability characteristics, as does the settlement of fines into the base of a hole. These may cause a problem in pressure measurement, but will certainly cause problems with permeability measurement from a standpipe piezometer installation unless a test is used that separates out the near well bore behaviour from that of the surrounding ground. Such tests usually use a period of flow and no flow. A typical example is a drill stem test (DST). 


\subsection{Cemented transducers}

Cemented transducer installations for aquifer and seam gas monitoring have been adopted from civil engineering for shallow installations in clay type materials, and from the oil and gas industry from drilling muds and casing cementing.

Where multiple pressure transducers are to be installed in single hole it is operationally desirable to avoid having to go through the procedure of placing staged gravel packs, bentonite seals and cement grout backfill. These impracticalities have also led to the use of sensitive diaphragm type transducers and fully grouted installations.

In civil engineering, early work by Penman (1961) demonstrated the suitability of diaphragm type transducers for pore pressure monitoring in fat London clays. This work was further developed by Vaughan (1969) into a fully grouted installation with design parameters established for the permeability of the grout relative to the in situ soil. The filter material around the sensor could then be removed allowing for nested sensor installations. Further work by McKenna (1995) on the fully grouted method demonstrated two essential criteria must be met, namely a short hydrodynamic lag time, and that the measured pressure is in fact the actual pore pressure in the soil. The first is satisfied by the use of transducers with very small movement of the sensing diaphragm. The second has found modest success in shallow installations by judicious design and testing of cement stabilised bentonite grouts. Development work then proceeded on the design and testing of grout mixes. Grout mix designs and practical recommendations were provided by Mikkelsen and Green (2001). However, there remains a difficulty in validation of the data from these installations.

While grouting transducers into a hole in a single operation had many advantages, there are many hurdles that need to be overcome. The least of these are the variability in mix designs and lack of quality control on site, but also include ensuring that there is connection to the ground being monitored, and that this connection is local and not influenced by fluid pressures around the rest of the borehole.

The application of installation techniques used in civil engineering to deeper monitoring wells may be problematic and can reduce the level of confidence in the data.

\subsection{Intra borehole connection}

It is important to ensure that there is no interconnection between each of the transducers in a cement grouted installation. Sources of interconnection are generally brought about by inappropriately designed or poorly mixed cement grouts. These can fail due to excessive permeability caused by:

- Solids separation - water to cement ratio too high.

- Fluid channelling within the cement grout - excessive bleed.

- Filtration from the cement grout into the formation - deep wells with high cement grout head.

- Shrinkage fractures within the cement grout.

- Gas channelling in the partially hydrated cement paste.

These problems can be overcome by using cement grouts that are of adequate density to avoid channelling, have additives to prevent separation, and do not shrink. Such grouts have their own set of behaviours that need to be overcome for an effective sensor installation. These include problems of very low permeability, gas migration from coal seams or other reservoirs, and potential hydro fracture of the ground through excessive cement grout pressure.

There also must be a test process to determine that there is no inter-connection between transducers within the same hole. 


\subsection{Connection to the formation}

How well the pressure sensing device is connected to the fluid in the ground is of primary concern. Not only must there be a reasonable expectation that a connection has been made, but this must then be validated.

In the case of cement grouted deep holes there is a real risk that the static pressure in the hole may lead to either fracturing of the formation or water within the cement grout being squeezed into the formation due to the filtration effect of the cement paste. Where this occurs, the density of the grout becomes significantly higher. The water in the cement grout is drawn out of the paste and the internal grout pore pressure may become very low during hydration. Under such circumstances, the cement grout becomes extremely impermeable thus causing serious lag in the time taken to register pressure changes. In some cases, this lag may be several months. What is required is a means of establishing that a connection to the ground has been made.

\section{$4 \quad$ How the ground dictates the monitoring system}

If we are going to put something into a borehole within the ground to monitor formation pore pressures, the device should ideally have the same properties as the ground surrounding the borehole so as not to interfere with flows and pressures that existed before drilling. This is difficult to achieve in practice; however, there are some factors that can be taken into consideration.

It is impractical to make the cement grout in a borehole have the same permeability as the various strata and ground it replaces, let alone a similar modulus. It is easier, and has fewer complications, to use a cement grout with a lower permeability. Such a cement grout reduces the level of uncertainty associated with intra borehole connection of formations of varying permeability. This is a different approach to that by Vaughan (1969) suggesting the cement grout could have a permeability no greater than two orders of magnitude higher than the surrounding soil, later revised by Contreras et al. (2008) to three orders of magnitude after finite element modelling. In addition, the volume of the borehole being filled with impermeable material should not be critical to the behaviour of the system.

In general, there is a need to have a cement grout in a hole that has similar stress strain behaviour as the soil it replaces. For example, there is a clear incompatibility between a peat and a hard cement grout in a situation where compaction is going to take place. If a generally plastic grout is used, care also needs to be exercised in its choice, lest substantial lateral deformation occur with vertical strain.

Clays may also expand, as in an over consolidated clay that is unloaded. In this case, severe loading may be placed on any sensor installation cable and the outcome is likely to be that the cable is pulled from a pressure transducer. The opposite may also occur when a cable is driven into the back of the transducer because the cement grout does not permit it to buckle to take up settlement.

Open rock joints are a challenge to monitor too. How can a seal be created on either side of the joint? An obvious simple solution, provided the joint remains in liquid, is to utilise swell packers. These are used in petroleum completions. Where the joint may be dry until recharge from a storm event, the swell packer will not set. An alternative is to use an inflatable packer to isolate a pressure transducer or the standpipe tip within the joint.

Where there is significant ground movement, such as around the settlement zone associated with goaf formation, or when hydro fracture stimulation of a gas field causes failure on a joint or fault, there is very little that can be done to keep the pressure monitoring systems and their cables intact. The only real option is to drill a large diameter hole and fill only the lower portion of it with cement grout so that some shearing movement can take place across the upper zone of the hole without shearing cables. To achieve this, the upper zone may be filled with bentonite.

In the cases where cement grouting is being undertaken to install transducers, there is a need to ensure that fracture of the formation does not take place due to the fluid pressure of the grout. The general approach to this is to reduce the density of the cement grout using fillers such as bentonite, fly ash, glass spheres, latexes or ground up plastics. However, these fillers can cause the cement grout to fail in other 
modes such as it segregates, shrinks, fractures, suffers from channels or simply has too great a permeability. The process of cement grouting the hole with a denser mix can avoid these problems but will need to be undertaken in stages so as to avoid in-hole pressures that lead to fracture of the ground. Stage grouting can be conducted with multiple grout pipes. It can also be achieved from a single grout pipe by incorporating a stage grouting valve that enables cement grouting to the level of the valve, flushing of the zone above the valve, and then cement grouting of the upper zone when the lower zone has set.

Pressure sensors require suitable tips to connect them with the ground. For example, a piezo-cone that is driven into the ground as part of cone penetrometer testing needs to have a robust cone that prevents clay from entering it and yet maintain enough permeability to measure pressure and its dissipation. The low permeability of the tip and the altered condition of the soil ahead of it need to be taken into account in analysing such measurements for permeability.

Where the measurement of soil water pressures in unsaturated ground is sought then suitable tips need to be used in front of the pressure transducer diaphragm so that they only connect with the moisture in the soil. The tips that are used are described as having high air entry values, meaning simply that a high air pressure is required to establish air flow through a saturated tip. Until this pressure difference exists capillary pressure prevents air flow. The purpose of such tips is to establish a continuous water phase through the tip and into contact with the water in the soil capillaries. The water pressure in the soil capillaries may certainly dip below atmospheric pressure. Some practitioners ascribe to the belief that the pressure may drop below zero absolute pressure, and is not limited by the vapour pressure of water at that temperature. This concept is somewhat difficult to fathom; absolute zero pressure is just that! The concept seems to be tied to the idea that the capillary pressure difference between water and air in the tip is limited by the tip's air entry character which may be of a very high magnitude. This, however, can only be tested in a positive pressure environment, as it is impossible to generate a pressure below absolute zero. In any case, it is impossible to measure pressures below water vapour pressure, as there needs to be a water filled space between the pressure transducer diaphragm and the porous tip.

\subsection{Packers}

Packers to seal sections of a borehole have been discussed in relation to rock joints. However, the packers have other uses in most installations. They may be used directly to seal sections of borehole or to seal within cemented and perforated casings (Figure 1). Such installations may be used for wells that are subsequently going to be used for production from multiple formations. Removal of packer systems in coal seam or other gas wells, however, require that the well be suspended prior to their removal so that a blowout does not occur. The use of this method on the basis that it permits servicing of the transducers is not justified due to the high cost of pulling such a system out of a 1,000 m coal seam gas well.

Packers can be used successfully with transducers in standpipes so as to remove the volume change associated with the rise and fall of water level in the pipe. 


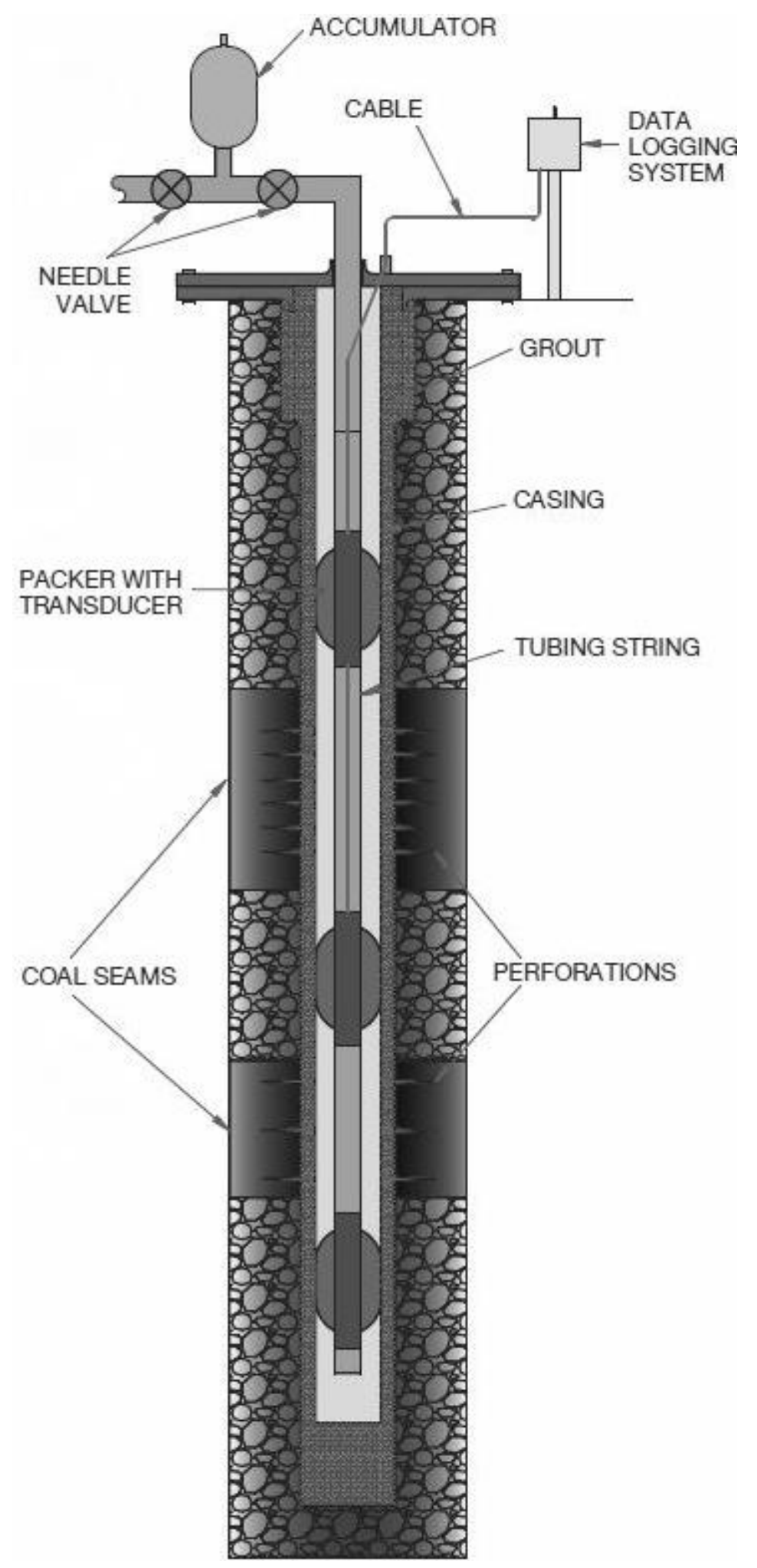

Figure 1 The concept of a multi-level packer assembly to monitor a cemented, cased and perforated production well

\section{Type 1 - cement displacement technique}

The cement displacement technique has been developed to overcome the known problems with existing cemented pressure transducer systems. It enables the use of low permeability cement grouts that avoid problems with intra-well connection between transducers and permits the transducers to operate in an 
installation that is independent from the grout formation interaction. It also provides a means by which intra-well connection can be tested and where communication with the formation to be monitored may also be tested. It has been successfully used in coal seam gas and groundwater operations by the authors.

\subsection{Cemented transducer}

This type of installation involves the placement of permanent pressure transducers in a borehole. In this application, a cement grout pipe is fitted with pressure transducers, cables and cement displacement lines and then lowered into the borehole. By preference, this is undertaken inside a casing or wireline drill pipe. This drill pipe is then withdrawn over the grout pipe assembly and the assembly is picked up from what will be a helically buckled form in the hole to locate the sensors at the predetermined positions. This is the situation shown schematically in Figure 2. Here a single transducer is shown hanging in the well by its cable. It is connected to a drilled block to which a filter is attached and so is a pressure relief valve. The pressure relief valve is designed to support the water column above it in the injection tube. This injection tube is either nylon or stainless steel depending on the depth and application.

- Figure 2(A) shows the operation of pumping water through the injection tubing to clear the filter.

- Figure 2(B) shows the hole being cement grouted.

- Figure $2(C)$ shows the filter being cleaned with a small quantity of water.

- Figure 2(D) shows the cement grout being displaced by water injection when it has reached a plastic state.
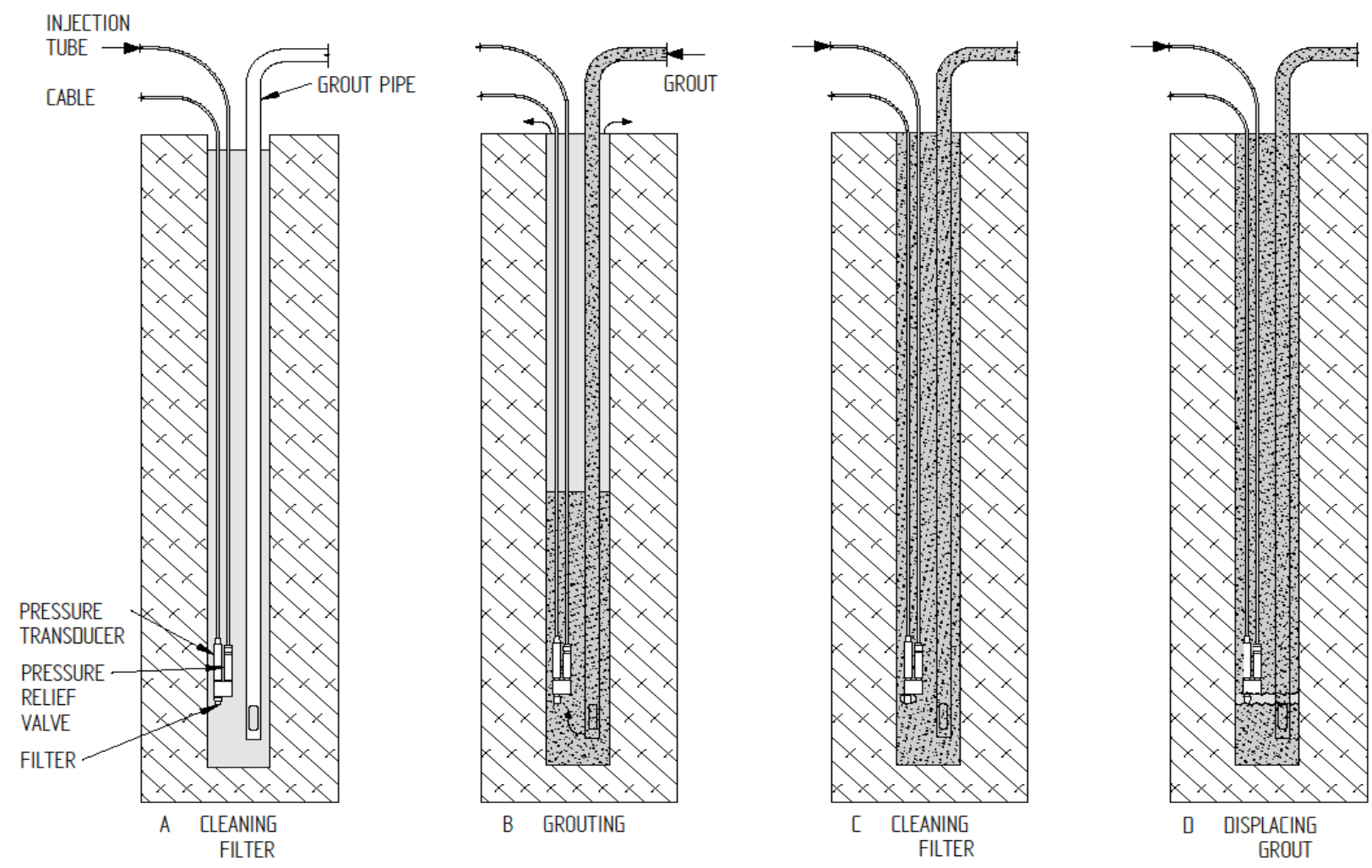

Figure 2 The installation sequence of a pressure transducer by cement displacement

The cement grout is allowed to set, and then the system may be tested by pumping more water through the injection tubing. The decay of pressure indicates that there is connection with the formation to be monitored. If there are multiple such pressure transducers in the installation, the borehole interconnection 
can also be tested by monitoring the pressure in the other transducers during and subsequent to injection. Of course, if the formations are connected then some pressure transient may be detected.

\subsection{Field results cement displacement}

Cement displacement technique has been used successfully to monitor coal seams for water and gas production.

Figure 3 shows the post grout injection fall-off curves for five transducers as the cement displacement tubes are pressurised and connection to the formation established. After initial pressurisation of the tubes to establish the connection, the seams are pressurised in sequence establishing a near perfect injection falloff curve. The small spikes on the pressure traces are caused by the pressurisation of nylon tubes passing to lower levels past the sensor and registering a small transient at the sensor tip.

This process validates the following:

- That the transducers are working.

- Connectivity from the sensor tip to the seam is established.

- No vertical connectivity between sensors exists.

In the latter case, this is demonstrated in Figure 3, where seams 2 and 3 are separated by a mere $300 \mathrm{~mm}$ of Tuff show no interconnection between the sensors. This technique, combined with consummate attention to detail, demonstrates that closely spaced formations can be effectively isolated for individual pore pressure measurement. This has a specific application for use in pulse drill stem testing to determining directional permeability of the seam being monitored as well as aquifer and coal seam or other reservoir monitoring. 


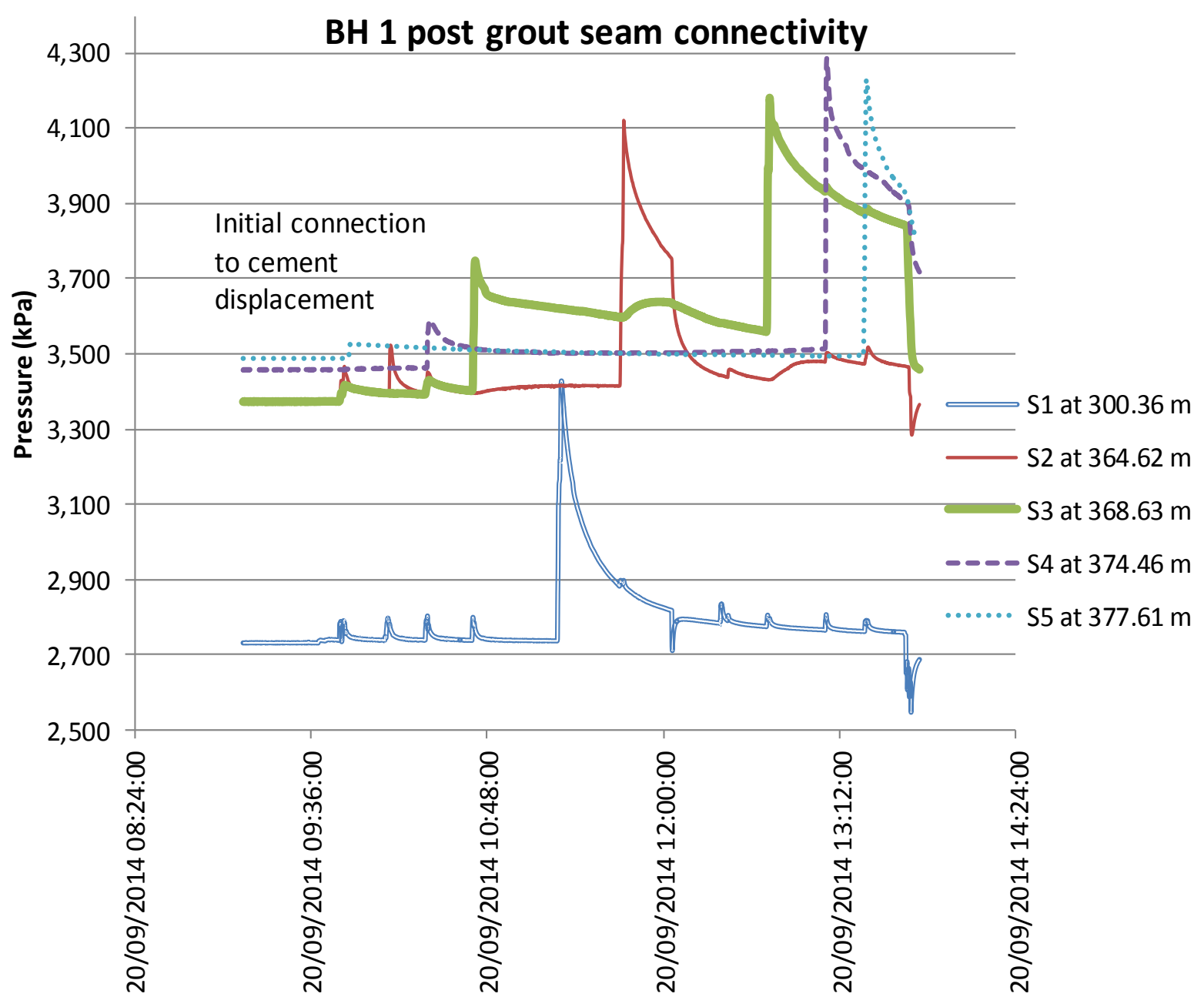

Figure 3 The plots from the post grout fluid injection of each cement displacement tube

\subsection{Cemented capillary tube}

As an alternative to the cemented transducer system described above it is possible to cement conduits into the hole that reach to the depth where monitoring is required but do not contain transducers. The transducers are inserted into the conduits with packers and sealed therein after the grouting process and connection to the formation is complete. By this method, the pressure transducers may be withdrawn for maintenance or calibration by deflating the packers and removing them with the transducer. If the conduit is of uniform size the packer may be inserted at any depth within it. However, if the desired result is just to monitor groundwater pressure which will not be drawn down excessively, then an adaptation may be made which reduces the size of hole, size of tubing, and overall cost.

In this system, capillary tubes are attached to the cement grout pipe and lowered down the borehole. These capillary tubes are connected to a larger diameter pipe in the upper part of the hole which may well be drilled oversize to accommodate these. This larger pipe serves to contain the packer and pressure transducer which will subsequently be installed. The capillary may be of moderate size or more conveniently may be of quite small size such as $4.8 \mathrm{~mm}$ outside diameter stainless tubing.

The process of installation is shown schematically using a single transducer as follows:

- Figure $4(\mathrm{~A})$ shows the system hanging in a borehole, water is injected to clear the filter.

- Figure $4(B)$ shows the cement grouting process.

- Figure $4(C)$ shows the filter being cleared by cement injection. 
- Figure 5(D) shows the grout being displaced.

- Figure 5(E) shows schematically a connection being made with the formation.

- Figure 5(F) shows the packer and transducer being installed following the setting of the cement grout.
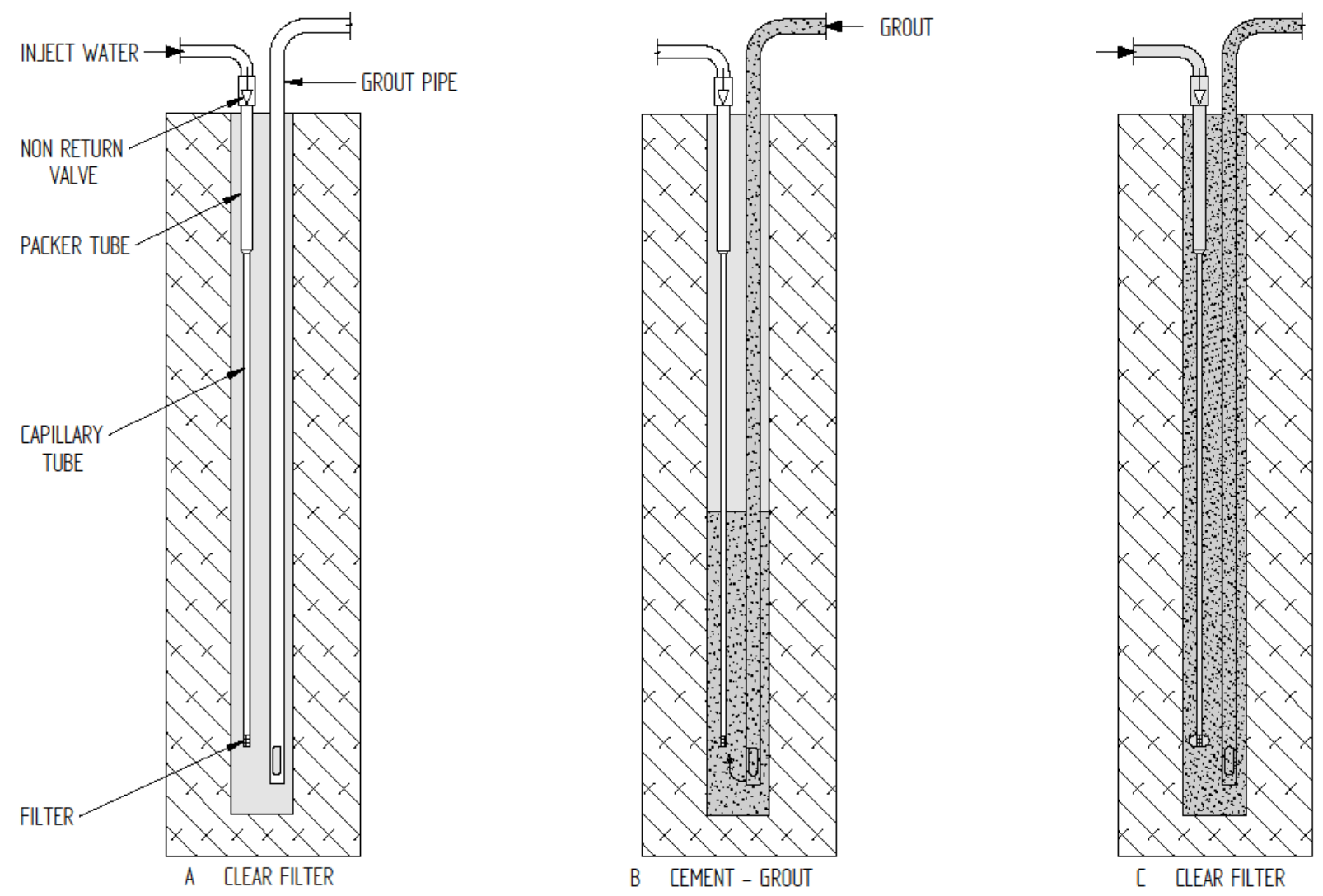

Figure 4 The first stage of installation of a pressure monitoring point using a capillary tube system 

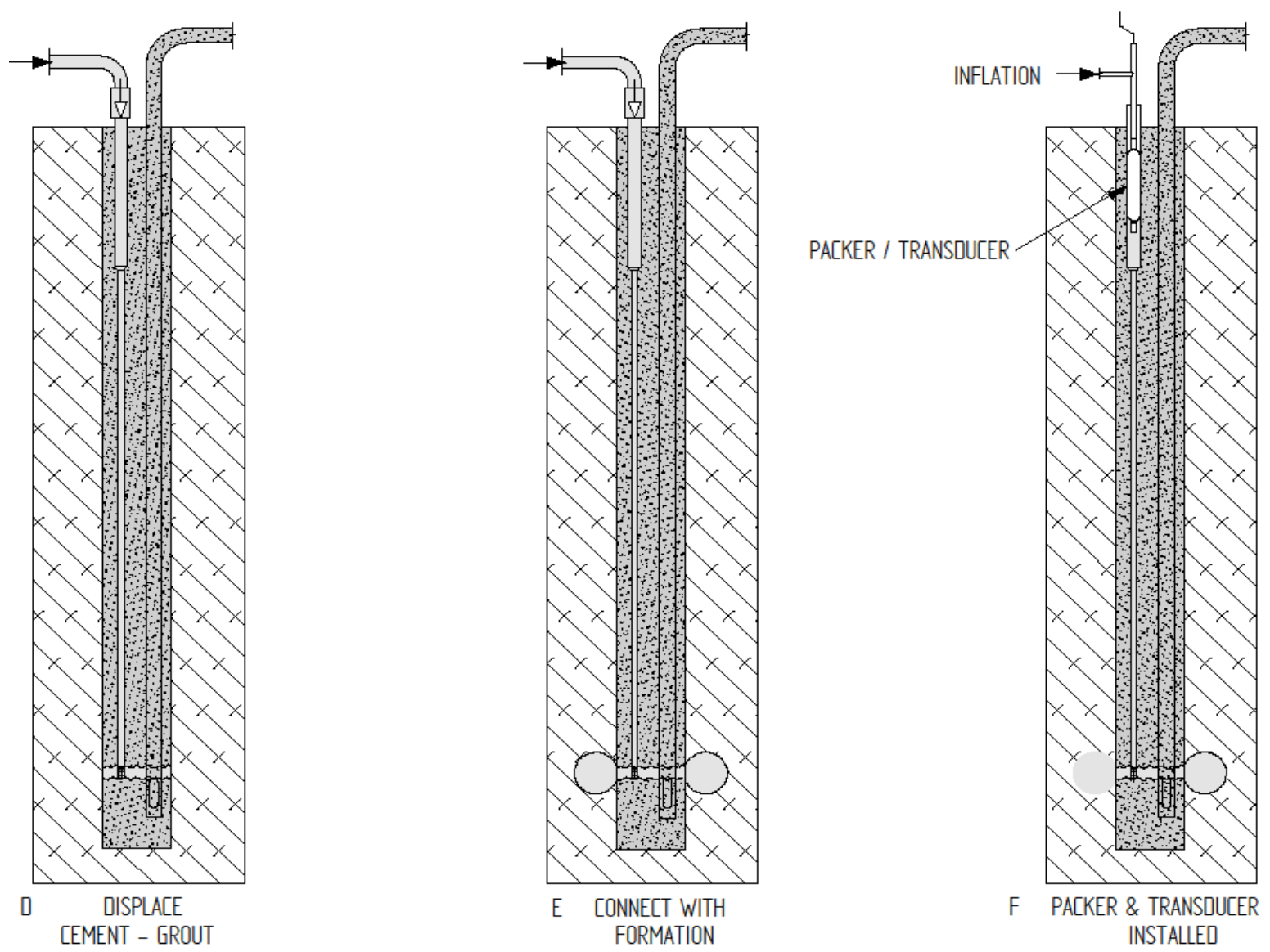

\section{Figure 5 The second stage of installation of a pressure monitoring point using a capillary tube system}

\section{Type 2 - soft soils - measuring pressure with deformation}

In soft soils there is a need to measure pressure, and frequently deformation too. Monitoring soft soils means that the monitoring system needs to be able to deform with the soil. A conventional cable does not do this very well, especially if the deformation is extension. The option of using sliding standpipe sections in which transducers are installed exists. However, to monitor at multiple levels in these installations, a variant of the multipacker assembly shown in Figure 1 is needed. This is simply difficult to fit into such standpipe assemblies and therefore they are restricted to single point monitoring.

The alternative that has been developed to monitor at multiple levels is one of a helical cable and tubing system. A helix is used because axial extension or compression is accommodated more easily. In this design, two types of pressure transducers are attached to the helix. The first type is a pore pressure monitoring transducer that have porous tips, and can be jacked into the borehole wall to monitor the pressure within the soil. The jacking fluid tube is part of the helix and common to all transducers. The second type of transducer measures absolute pressure of water in an additional helical tube. This additional helical tube has the water head maintained at a constant level within it. Once installed, the hole may then be cement grouted with a suitable highly plastic backfilling (clay) mix.

In operation, the system is designed to enable the measurement of pore pressure and settlement or expansion of the ground. Pore pressure is measured directly by the transducers that are jacked into the ground whilst the ground movement is measured by the transducers monitoring water pressure in the helical tubing string which has a regulated head at surface. The ground movement measured is relative to that surface level which requires surveying. 
The sequence of installation is shown in Figures 5 and 6.

- Figure $6(\mathrm{~A})$ shows a grout pipe installed in $\mathrm{PQ}$ core drill pipe. The pipe has a weight at the base to hold it down.

- Figure $6(B)$ shows the helical instrumentation string being installed through the drill pipe.

- Figure $6(C)$ shows the $P Q$ pipe being withdrawn over the top of the helical string.

- Figure 7(D) shows the piezometer tips being jacked into the side wall of the borehole.

- Figure $7(E)$ shows the hole being cement grouted through the grout pipe using a very plastic grout.

- Figure $7(\mathrm{~F})$ shows the installed system with the cement grout pipe having been withdrawn prior to the setting of the cement.

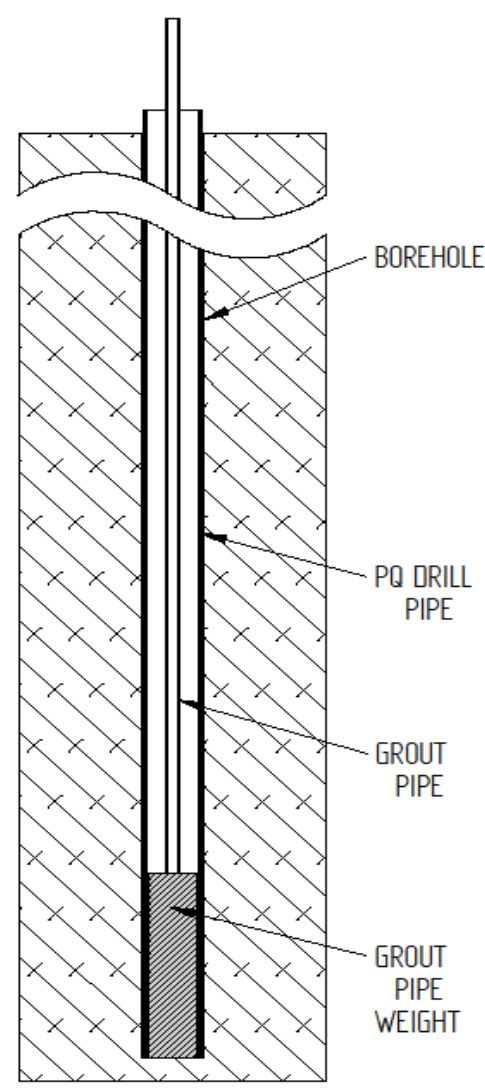

A GROUT PIPE INSTALLED

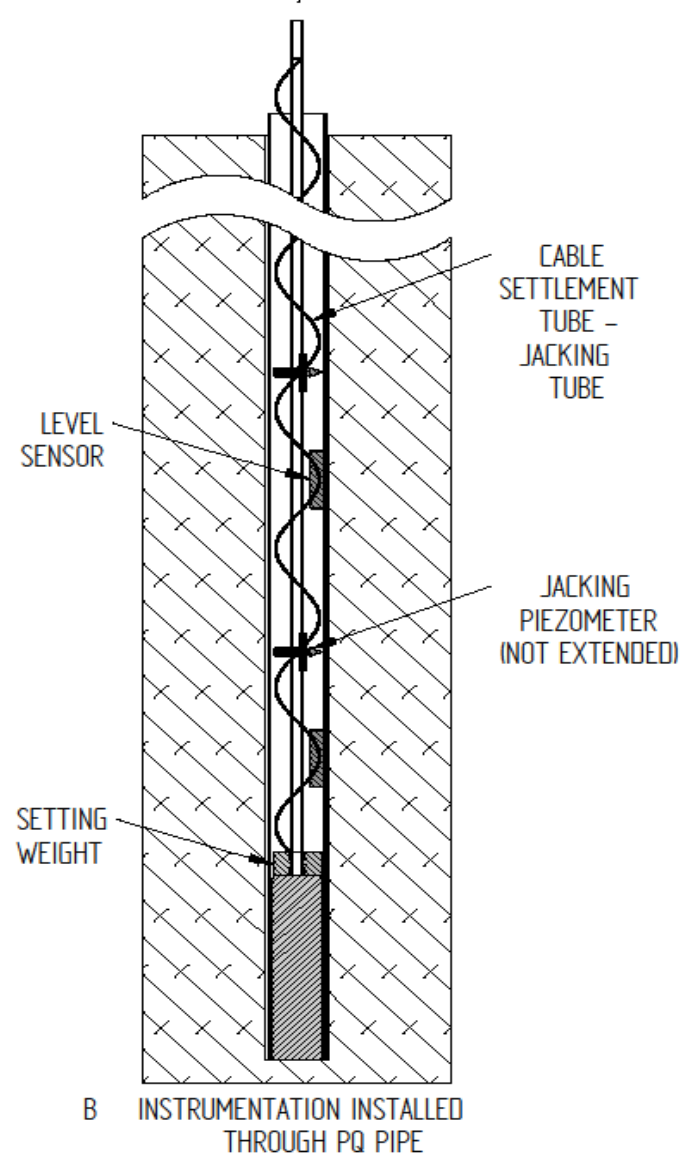

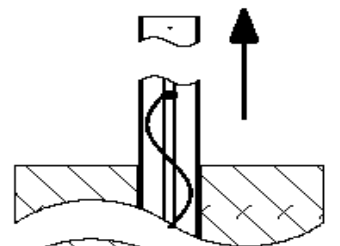

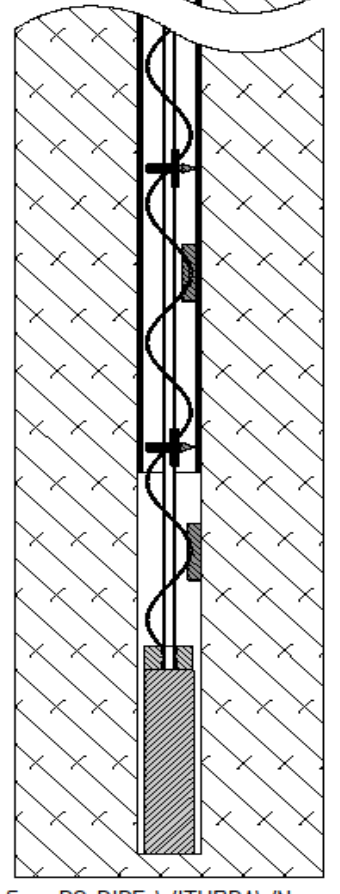

[ PQ PIPE WITHDRAWN

Figure 6 The first stage of the sequence of installation of a helical tube pressure and settlement monitor 

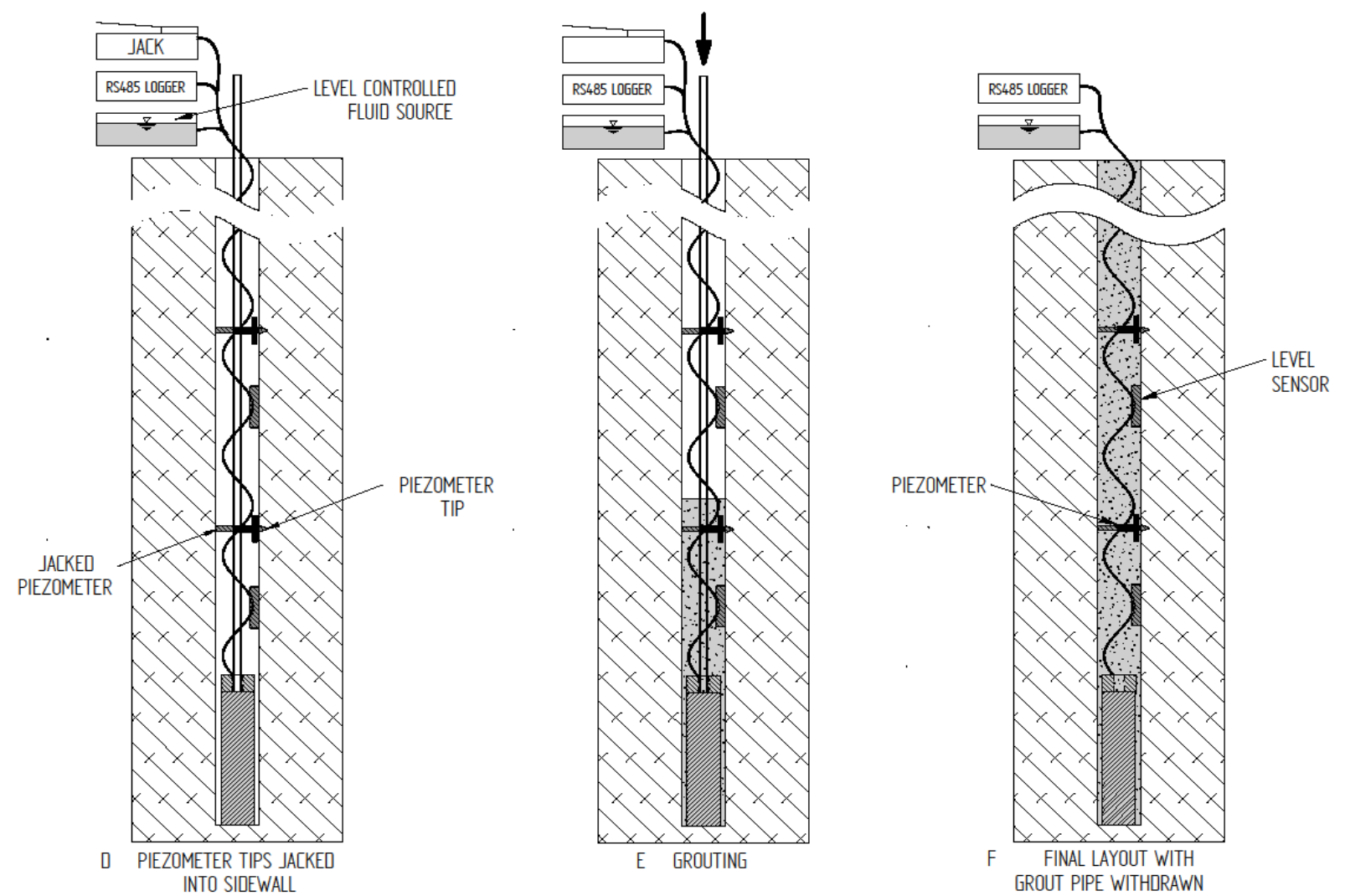

Figure 7 The second stage of the sequence of installation of a helical tube pressure and
settlement monitor

\section{Conclusion}

This paper endeavours to explain some of the complications of measuring fluid pressure in different environments within the ground. It also presents two new systems to install pressure sensing systems. The first is the cement displacement system which can be used in soils, aquifers or in coal seam gas reservoirs. This system enables multiple pressure sensing points to be created within the hole, all of which can be tested for connection to the formation being monitored and for borehole intra connection. Examples of installations are presented where this installation has been successfully employed enabling pressures to be monitored above and below a narrow tuff band between two coal seams.

Finally, the paper presents a new system to enable the monitoring of both pressures and deformation that is suitable for soils subject to high deformations. It is particularly suitable to monitor soft ground consolidation. However, it could also be used to measure the creation of negative pore pressure developed in an over-consolidated clay that has been unloaded during excavation.

Aspects of the techniques described are the subject of patent applications.

\section{References}

Contreras, IA, Grosser, AT \& Ver Strate, RH 2008, 'The use of fully-grouted method for piezometer installation', Geotechnical News, vol. 26, pp. 30-37.

McKenna, GT 1995, 'Grouted-in Installations of piezometers in boreholes', Canadian Geotechnical Journal, vol. 32, pp. 355-363.

Mikkelsen, PE \& Green, GE 2003, 'Piezometers in fully grouted boreholes', in F Myrvoll (ed.), Proceedings of the Sixth International Symposium on Field Measurements in Geomechanics, CRC Press, London, pp. 545-553.

Neels, B \& Gray, I 2014, 'Fluid pressure monitoring in deep cement grouted boreholes', in N Aziz, B Kininmonth, J Nemcik, D Black, J Hoelle \& I Cunbulat (eds), Proceedings of the 14th Coal Operators' Conference, Australasian Institute of Mining and Metallurgy \& Mine Managers Association of Australia, pp 301-308.

Penman, ADM 1961, 'A study of the response time of various types of piezometers', Proceedings of the Conference on Pore Pressure and Suction in Soils, Butterworths, London, pp. 53-58.

Vaughan, PR 1969, 'A note on sealing piezometers in boreholes', Geotechnique, vol. 19, no. 3, pp. 405-413. 